\title{
Retraction notice for: "Risk factors for early-onset ventilator-associated pneumonia in aneurysmal subarachnoid hemorrhage patients" [Braz J Med Biol Res (2018) 51(7): e6830]
}

J.B. Cui, Q.Q. Chen, T.T. Liu, and S.J. Li

Neurosurgery Intensive Care Unit, Weifang People's Hospital, Weifang, China

Retraction for: Braz J Med Biol Res | doi: 10.1590/1414-431X20176830 | PMID: 29791584

The Brazilian Journal of Medical and Biological Research was contacted by one specialist questioning the validity of this study.

The Editors decided to retract the article: "Risk factors for early-onset ventilator-associated pneumonia in aneurysmal subarachnoid hemorrhage patients" that was published in volume 51 no. 7 (2018) (Epub May 17, 2018) in the Brazilian Journal of Medical and Biological Research <http://dx.doi.org/10.1590/1414-431X20176830> PMID: 29791584 | PMCID: PMC5972009

The authors agreed that this article should be retracted. All authors will be prohibited to publish in the Brazilian Journal of Medical and Biological Research in the future. 


\title{
Risk factors for early-onset ventilator-associated pneumonia in aneurysmal subarach roid hemorrhage patic ats
}

\author{
J.B. Cui, Q.Q. Chen, A.Liu an, o.J. Li \\ Neurosurgery Intensive Care Unit, Weifang Peorle's spital, eifang, China
}

\begin{abstract}
This study aimed to investigate the risk factors related to ventilator-acquired pney (VAP) aneurysmal subarachnoid hemorrhage (SAH) patients. From January 2011 to December 2015, a single-c er rospective study including $200 \mathrm{SAH}$ patients requiring mechanical ventilation (MV) $\geqslant 48 \mathrm{~h}$ was performed. The clin $\mathrm{d}$ se patients were collected and analyzed. The age range of the patients were 41-63 and $72(36 \%)$ were male. The gow coma scale score range was 5-15 and the Simplified Acute Physiology Score II range was 31-52. One $h$ and $y$-eight (74\%) patients had a World Federation of Neurosurgeons (WNFS) score $\geqslant$ III. Aneurysm was secured h hal vascular coiling procedure in $168(84 \%)$ patients and $94(47 \%)$ patients presented VAP. Male gender $(\mathrm{OR}=2.25,95-1.15-4.45)$, use of mannitol $(\mathrm{OR}=3.02,95 \%$ $\mathrm{Cl}=1.53-5.94)$ and enteral feeding above $20 \mathrm{kcal} \cdot \mathrm{kg}^{-1} \cdot \mathrm{day}^{-1}(\mathrm{OR}=2.90,9 \mathrm{~V} \quad \mathrm{Cl}=1.26-6.67)$ after day 7 were independent factors for VAP. Patients with early-onset VAP had a longer durat f sedation $(P=0.03), M V(P=0.001)$ and ICU length of stay $(P=0.003)$ and a worse Glasgow Outcome Scale score $(P<C \quad 01), \mathrm{b}$ did not have a higher death rate.
\end{abstract}

Key words: Ventilator-acquired pneumonia; Aneurysmal s arac. id $r$ norrhage; Risk factors; Multivariate analysis; Pathogen

\section{Introduction}

Aneurysmal subarachnoid hemorrhage $(\mathrm{SAH})$ threatening condition with increasing $r$ ulence ove the years (1). In most cases, mechanical entilatic (MV) and intensive care unit (ICU) hospitaliza $n$ are andatory. SAH patients frequently present with nos al infections and pneumonia, which might a necently, a few studies have reported on er ac -acquired pneumonia (VAP) in SAH pat.

Among ICU patie $O, \vee P$ ren ins a major cause of infection (3). Severa reported VAP in specific populations, s' $\mathrm{s}$ as d trauma patients (4-6). In that population, a $y$ revalen of up to $40 \%$ was found, with involvement or spe pathogens $(5,7)$. VAP can result in substanti morbidity d high health-care costs, but a rather $v m$ cality in head trauma patients $(4,7)$. Most episode VAP in trauma patients occur in the first $7(5, \quad$, vious studies have pointed out specific sk fa .ors, invulding the use of barbiturates (7-9), contin$n$ (10), intra-cranial hypertension (5), or delayed en. Il feeding (7). In the present study, we aimed to determ, ne the risk factors and pathogens involved in the early-onset VAP in SAH patients in China.

\section{Patients and Methods}

\section{Patients}

From January 2011 to December 2015, we conducted a retrospective single-center study in the ICU of our hospital. Patients hospitalized for an aneurysmal SAH and requiring $M V \geqslant 48 \mathrm{~h}$ were included in the study. Exclusion criteria were: 1) patients with an intra-cerebral hemorrhage from another origin, including arterio-venous malformation, non-aneurysmal subarachnoid hemorrhage, or non-traumatic intra-cerebral hemorrhage; 2) patients who were transferred to another center after aneurysmal coiling and could not fulfill follow-up for the primary endpoint; 3) patients who died in the first 2 days of ICU hospitalization. Written informed consent was obtained from all patients and the study was performed in accordance with the Ethics Committee approval of Weifang People's Hospital.

\section{Management of SAH patients \\ Computed tomography (CT) brain scan was used for aneurysmal SAH diagnosis. The aneurysm was confirmed}


during an arteriography with an endovascular coiling in the first $24 \mathrm{~h}$. The choice of the treatment modality (coil or clip method) was made when a consensus was reached about the disease between the neurosurgeon and neuroradiologist. Patients with a Glasgow coma scale (GCS) score $\leqslant 8$ were sedated with a continuous intravenous infusion of fentanyl $\left(2-5 \mu \mathrm{g} \cdot \mathrm{kg}^{-1} \cdot \mathrm{h}^{-1}\right)$ or sufentanil $\left(0.2-0.5 \mu \mathrm{g} \cdot \mathrm{kg}^{-1} \cdot \mathrm{h}^{-1}\right)$ and midazolam $\left(0.2-0.5 \mathrm{mg} \cdot \mathrm{kg}^{-1} \cdot \mathrm{h}^{-1}\right)$ according to the guidelines (11). Cerebral perfusion pressure was maintained $\geqslant 60 \mathrm{mmHg}$ by using norepinephrine. Intra-cranial hypertension was defined as an intracranial pressure (ICP) $\geqslant 25 \mathrm{mmHg}$ and treated by a bolus of mannitol $(0.5 \mathrm{~g} / \mathrm{kg})(11)$. When plasmatic osmolarity was $\leqslant 320 \mathrm{mOsm} /$ $\mathrm{kg}$, mannitol was applied. Hypertonic saline was not employed during the study period. When ICP remained elevated after osmotherapy, barbiturates were injected (sodium thiopental), with an intravenous (iv) bolus of $2-3 \mathrm{mg} / \mathrm{kg}$, followed by a continuous infusion of $2-3 \mathrm{mg} \cdot \mathrm{kg}^{-1} \cdot \mathrm{h}^{-1}(12)$. Nimodipine (1-2 mg/h, iv) was administrated at ICU admission. As soon as the enteral feeding started, nimodipine was administered via enteral feeding tube (360 mg/day) during 21 days (1). Screening of vasospasm was performed once a day in the middle cerebral artery by Transcranial Doppler (TCD). An arteriography was performed whenever the mean artery flow velocity assessed by TCD was $50 \%$ higher than that on the first day, or above $120 \mathrm{~cm} / \mathrm{s}$ (13). Bec es, arteriography was also performed when an uney aine fever or a new neurologic deficit appeared. The dingr. of vasospasm was given during arteriography b an exp enced neuro-radiologist. Before starting e nutrition, a chest X-ray was used to confirm location of the $L$. If the feeding tube in the stomach. Patients w ad continu uusly with a peristaltic feeding pump. No $\mathrm{w}$ ten ent al nutrition protocol was available in our ICU durin the per d of study and nutrition procedures were loft to the physician's discretion. Achieving an tw thrition threshold of $20 \mathrm{kcal} \cdot \mathrm{kg}^{-1} \cdot$ day $^{-1}$ was deeme to appropriate for our research needs accordi the insensus (14). Due to the lack of specific $r$ omr ndatic s for ICU population, protocoled weaning not available during the period of study. $V$ aning rted as soon as ICP control was deemed appro Sedat and morphinomimetic agents were progressivel, amoved when ICP was controlled. Criteria ar recommen itions in the most recent guidelines for ext atio (15) were not available during the period of study war eft to the attending physician. In spite of ence ang early tracheostomy (16), this proceare as perturmed only in patients with a prolonged MV

\section{1 uaye, (16).}

Prima y outcome

According to the criteria of the American Thoracic Society (ATS) (3), VAP was defined as the presence of a new or progressive pulmonary infiltrate on the chest radiography and two of the following items: hyperthermia $\left(\geqslant 38^{\circ} \mathrm{C}\right)$ or hypothermia $\left(\leqslant 36^{\circ} \mathrm{C}\right)$, leukocytosis $(\geqslant 12,000 / \mathrm{mL})$ or leukopenia ( $\leqslant 4000 / \mathrm{mL}$ ), and purulent pulmonary secretions. Patients suspected of having pneumonia ur erwent either endotracheal aspirates or fiberoptic bro nos spy to obtain samples by means of protected spe or orust or bronchoalveolar lavage. The diagnosis was 'velr' more than $10^{3}, 10^{4}$, or $10^{6}$ colony forming units (CF $\mathrm{mL}$ were found on protected specimen brush, "oncho yeolar lavage, and endotracheal aspirat espe ur . Pneumonia was considered ventilato associated unen onset occurred after tracheal intubat Early nset of VAP (EOVAP) was defined as AP in in the first 7 days after orotrachea' ntuk ion (5). VAP occurring after the 7th day was ined as e-onset VAP (5). All episodes of suspecte. $V A_{\text {, }}$ 'ere prospectively evaluated during a weekly ff mee ${ }_{4}$ with attending neurointensivists, infe ous disease specialists, microbiologists, and hygiene $s_{\text {, }}$ gnosis was upheld according to the ATS criter

\section{Data col tio}

Gender, Simplified Acute Physiology Score II (SAPS II), medical hist , GCS score on scene, World Federation of osurgeons score (WFNS), Fisher score, aneurysm locat. surgery upon admission, ventriculostomy realization, t e of aneurysm, clip or coiling, and antibioprophyere prospectively recorded. Stress-ulcer prophylaxis, baisiturates, corticosteroids, insulin therapy, length of edation, and nutrition data were also noted during the ICU stay. ICU length of stay (LOS), mortality rate at the time of ICU discharge, and duration of sedation and of MV were calculated.

\section{Statistical analysis}

All statistical analyses were performed in SPSS 18.0 (SPSS Inc., USA). Continuous data are reported as medians and percentiles (25-75\%) or means \pm SD, and categorical data as numbers and percentage. The $\chi^{2}$ or Fisher's exact test was employed for qualitative variables, and Student's $t$-test or the Wilcoxon non-parametric test was used for quantitative variables. Potential risk factors were determined by multivariate logistic regression model and backward selection. The final model is presented with crude odds ratios (OR) and 95\% confidence intervals $(\mathrm{Cl}) . \mathrm{P}<0.05$ was considered statistically significance.

\section{Results}

\section{Patient demographic data}

A total of 200 patients who met the criteria were included. The age range of the patients was 41-63 and $72(36 \%)$ were male. The GCS score range was $5-15$ and the SAPS II range was 31-52. One hundred and forty-eight (74\%) patients had a WFNS $\geqslant$ III and 146 (73\%) had a Fisher score of 4 . One hundred and twenty-eight $(64 \%)$ patients were treated with ventriculostomy. Aneurysm was secured with an endovascular coiling procedure 
in $168(90 \%)$ patients. Fifty (25.0\%) patients received $2 \mathrm{~g}$ of cefazolin during a ventriculostomy procedure (antibiotic prophylaxis), and antibiotics were systematically discontinued after surgery. One hundred and ninety (95\%) patients received stress ulcer prophylaxis. Forty-eight (24\%) patients received antacids and $142(71 \%)$ patients received sucralfate. Ninety-eight $(47 \%)$ patients presented a VAP, $80(40 \%)$ of which were EOVAP. Among the 80 patients with EOVAP, 14 (17.5\%) patients displayed criteria of acute lung injury or acute respiratory distress syndrome. Forty-one $(20.5 \%)$ patients died in the ICU during the study period. The median duration of sedation was $11(6-15)$ days, the median duration of MV was 19 (11-29) days, and the median ICU LOS was 23 (15$34)$ days. Twenty-eight (14.0\%) patients underwent a late tracheostomy in order to wean $\mathrm{MV}$, performed during a median of 28 (22-32) days.

\section{Univariate analysis of the risk factors related to EOVAP}

According to the univariate analysis, male gender, seizures before intubation, use of mannitol, and enteral feeding above $20 \mathrm{kcal} \cdot \mathrm{kg}^{-1}$. day ${ }^{-1}$ before day 7 showed significant difference between patients with or withou ${ }^{+}$ EOVAP (Table 1).

\section{Multivariate analysis of the risk factors related to EOVAP}

The risk factors included into the multivaria' an ' 'sis were male gender, active smoking, seizures bu uba tion, ventriculostomy, use of mannitol, and entera. ed s above $20 \mathrm{kcal} \cdot \mathrm{kg}^{-1} \cdot$ day $^{-1}$ after day 7 . As shown in Ta. 2 , male gender $(\mathrm{OR}=2.25,95 \% \mathrm{Cl}=1.15-4.4 \mathrm{~V}$, we of $r$ annitol $(\mathrm{OR}=3.02,95 \% \mathrm{Cl}=1.53-5.94)$ and eral $\mathrm{d}$ above $20 \mathrm{kcal} \cdot \mathrm{kg}^{-1} \cdot$ day $^{-1}(\mathrm{OR}=2.90, \% \mathrm{Cl}=1.26-6.07)$ before day 7 were independent factors $f$ EOVAF

\section{Pathogens analysis of ${ }^{\prime}$, ear and late-onset VAP in SAH patients}

Bacterial culture etrie a single bacterium in 73 EOVAP and multir nicroory isms in seven. As shown in Table 3, the ain athogen involved was methicillinsusceptible S. ' $v$ ' aureus (MSSA) (35\%). Other pathogens were эmophilus influenzae (28\%), Streptococcus moniae $\%$ ), and Enterobacteriaceae (11\%). MSSA (5 1\% Enterobacteriaceae (42.9\%) were the main pathc $s$ in 14 late-onset VAP.

\section{ts in the ICU}

ents with EOVAP had a longer duration of sedation $(P=0 .(), M V(P=0.001)$, and ICU LOS $(P=0.003)$ and $a$

Table 1. Risk factors analysis for early-c acquired pneumonia (EOVAP) in patients with aneurysmal subarachnoid hemorrhagr $S A \mathrm{~A}$, 
Table 2. Multivariate analysis of the risk factors for early-onset of ventilator-acquired pneumonia.

\begin{tabular}{llll}
\hline Variables & OR & $95 \% \mathrm{Cl}$ & P value \\
\hline Gender (male) & 2.25 & $1.15-4.45$ & 0.01 \\
Use of mannitol & 3.02 & $1.53-5.94$ & 0.001 \\
Achievement of enteral feeding $\geqslant 20 \mathrm{kcal} \mathrm{kg}^{-1} \mathrm{day}^{-1}$ & 2.90 & $1.26-6.67$ & \\
before day 7 & & \\
\hline OR: odds ratio; $\mathrm{Cl}$ : confidence interval. & \\
\\
Table 3. Pathogens analysis of the early- and late-onset ventilator-acquired pneumon \\
subarachnoid hemorrhage patients.
\end{tabular}
subarachnoid hemorrhage patients.

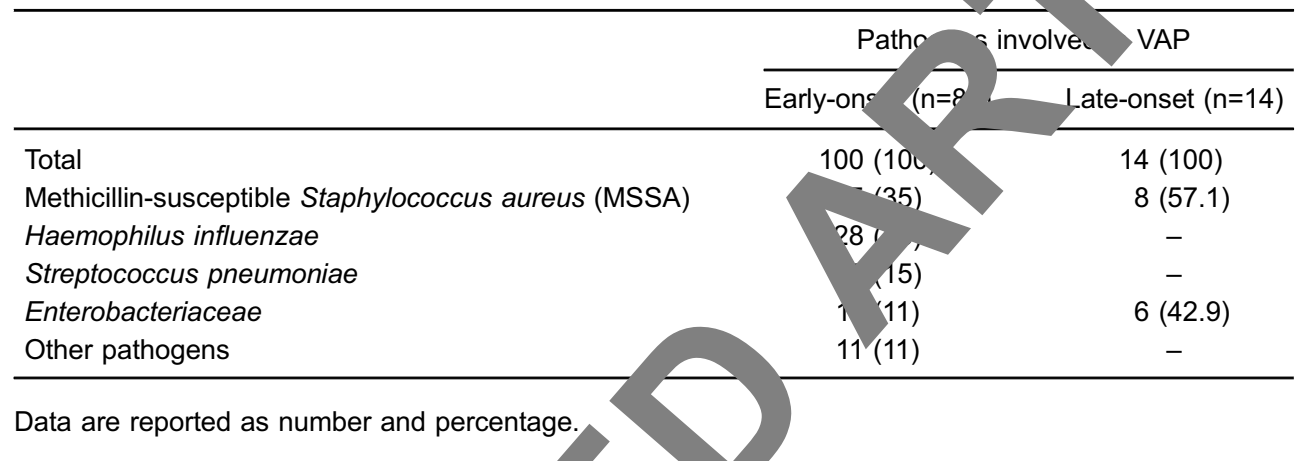

Table 4. Events in the intensive care unit (ICU).

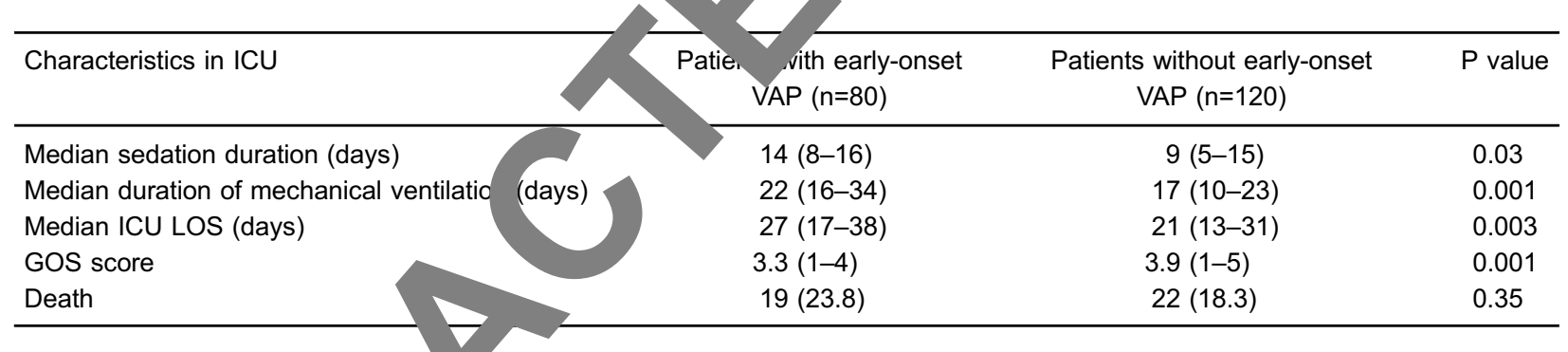

Data are reported as medi and centiles (25-75\%). VAP: ventilator-acquired pneumonia; LOS: length of stay; GOS: Glasgow outcome scale. Student' -tes or the ilcoxon non-parametric test was used for statistical analyses.

lower GOS scc (P D 01$)$. Death rate was $23.8 \%$ in patients wi EOVAP (Tabi 4).

Discy sio

he 0 study, 94 (47\%) patients presented with $4 P$, sich was comparable to a previous study (17). The multivariate analysis showed that male gender, us $f$ mannitol, and delayed enteral nutrition were confirmea as the independent risk factors for EOVAP, while MSSA was found as the main pathogen of EOVAP.

According to previous reports, the incidence of VAP in the ICU was about $40 \%(5,7)$ when the patient presented with traumatic brain injury (18). The incidence of VAP in $\mathrm{SAH}$ patients was rather high in the current study, which was comparable to that in head-trauma patients, indicating a higher susceptibility to nosocomial pneumonia in braininjury patients. Previous studies have shown that brain injuries could induce a state of nosocomial infectionsassociated immune paralysis (19). Recently, Frontera et al. (2) found a lower incidence of nosocomial pneumonia (20\%). MV was considered highly associated with nosocomial pneumonia, suggesting that it is of critical importance in patients with SAH requiring MV. In head trauma patients $(4,5,7)$, EOVAP was associated with increasing length of MV and ICU LOS, but the mortality rate was not high in SAH patients.

Moreover, we found that enteral nutrition was independently associated with EOVAP. In a previous study, enteral nutrition was reported to play an important role in nosocomial infections, especially VAP in head trauma 
patients $(7,20)$. However, enteral feeding was limited due to the risk of micro-inhalation. Poulard et al. (21) reported that early initiation $(<48 \mathrm{~h})$ associated with a rapid increase in the enteral nutrition intake was not correlated with VAP in a general ICU population. Furthermore, Reignier et al. (22) recently showed that residual gastric monitoring was not mandatory to prevent VAP but led to less enteral intake in patients. These results suggested that early nutrition, without residual gastric monitoring, could be safely performed in brain-injured patients. In accordance with previous consensus on enteral nutrition in the ICU, we upheld the threshold of $20 \mathrm{kcal} \cdot \mathrm{kg}^{-1} \cdot \mathrm{day}^{-1}$ within the period $<7$ days (14). Our results suggested an association but not a causation between low enteral nutrition intake and early-onset VAP. In brain-injured patients, an evidencebased extubation readiness bundle including early enteral nutrition was safe and decreased the length of MV (23).

We also found that use of mannitol was independently associated with VAP. Several studies have found that barbiturate was considered a risk factor for immunosuppression and VAP in brain-injured patients $(5,7,9)$. To date, no authors have reported mannitol as a risk factor for VAP, but some immunomodulatory effects of osmotherapy have been described with hypertonic saline solution in the setting of experimental hemorrhagic shock. Some authors found a decrease of TNF production and polymo nuclear neutrophils activation with mannitol (24). in th other hand, other investigators have found a dere. of pro-inflammatory cytokines and $\mathrm{T}$ lymphocy ${ }^{+}$prolite tion in the setting of hemorrhagic shock (2 it -crania hypertension exhibited some immunosuppressiv functions that might increase the suscept ... to pneurionia in the setting of brain-injured immune ysfunc ${ }^{+4} \mathrm{n}(19,25)$. In all studies focusing on brain-injur patier, barbiturates and mannitol were used to re intra-cranial hypertension (12). Barbiturate cund mannitol were administered to most patients i sprayed an immune impairment in the prese f VA 18). It must be kept in mind that mannitol is oba $y$ a $\mathrm{cc}$. founding factor and it is hard to delineate ole of mannitol versus elevated ICP on e ge, is of VAP.

In addition found th. male gender was associated with an increased $h$ of VAP. Few experimental data have pointed o' some prote ve effects of estrogen after hemorrhage d, $n$ ably, phagocytosis capacity on Kupffer cells (26). To , no rmonal therapy is available in the ICU to d $n$ mial infections, but this could be condere as a potential target in the future.

\section{Re rences}

1. Connolly ES Jr, Rabinstein AA, Carhuapoma JR, Derdeyn CP, Dion J, Higashida RT, et al. Guidelines for the management of aneurysmal subarachnoid hemorrhage: a guideline for healthcare professionals from the American Heart Association/american Stroke Association. Stroke
Pathogens involved in EOVAP were MSSA, Haemophilus influenzae, and Streptococcus pneumonia MSSA is also the main pathogen in head-trauma $p$ ? nts yith $\operatorname{VAP}(5,7)$. This pathogen remains highly spe of VAP in brain--injured patients and is not found wits ucb $A$ high prevalence in medical patients $(17,27,28)$. Haem, philus influenzae and Streptococcus pne sniae also frequently retrieved among head ma if s $(5,7)$. Based on the risks of multidrug-r istant bacte. a, the cutoff of early- and late-onset VAP $h$ been $\S$ at day 5 after the initiation of MV by the la con an consensus (3). However, in head-traum pati Bronchard et al. (5). found that pathogens nained ceptible to most of the antibiotics recomi ena by the ATS guidelines in the first 7 days after th nitiation MV. Therefore, we chose this cut-off, as hy othesized that pathogens involved in VAP in pat " would be similar to those in head-trauma pat ' $s$. In the setting of late-onset VAP, MSSA v retr all along with Enterobacteriaceae. These $r \in$ Its asted that early-onset VAP flora in patients w $\mathrm{AH}$ was similar to that in patients with head trauma and 7-days cut-off determining the emergence tibiotic-resistant pathogens may be used in patients with $\mathrm{AH}$. However, this question was not completely answe d by our study. Further studies are needed to ' $\mathrm{f}$ these results.

here are several limitations in this study. First, single center retrospective study may result in bias in the multivariate analysis results. Second, incomplete information could fail to determine the effect of VAP on the neurological outcome or mortality of the patients. Third, a short-term infusion of antibiotics could reduce the rate of VAP. Finally, the Clinical Pulmonary Infection Score was not determined, which could result in controversies on VAP diagnosis.

VAP is frequently present in SAH patients requiring MV. We found that male gender, use of mannitol, and delayed enteral nutrition were confirmed as independent risk factors for EOVAP, while MSSA was found as the main pathogen for EOVAP. According to previous studies (7), enteral nutrition strategy is recommended for $\mathrm{SAH}$ patients in general surgical ICU patients (20) and for braininjured patients (23).

\section{Acknowledgments}

This work was financially supported by the Weifang Science and Technology Bureau (No. 2016RKX031).

2012; 43: 1711-1737, doi: 10.1161/STR.0b013e3182 587839 .

2. Frontera JA, Fernandez A, Schmidt JM, Claassen J, Wartenberg KE, Badjatia N, et al. Impact of nosocomial infectious complications after subarachnoid hemorrhage. 
Neurosurgery 2008; 62: 80-87; discussion 87, doi: 10.1227 / 01.NEU.0000311064.18368.EA.

3. Guidelines for the management of adults with hospitalacquired, ventilator-associated, and healthcare-associated pneumonia. Am J Respir Crit Care Med 2005; 171: 388-416, doi: 10.1164/rccm.200405-644ST.

4. Cook A, Norwood S, Berne J. Ventilator-associated pneumonia is more common and of less consequence in trauma patients compared with other critically ill patients. J Trauma 2010; 69: 1083-1091, doi: 10.1097/TA.0b013e3181f9fb51.

5. Bronchard R, Albaladejo P, Brezac G, Geffroy A, Seince PF, Morris W, et al. Early onset pneumonia: risk factors and consequences in head trauma patients. Anesthesiology 2004; 100: 234-239, doi: 10.1097/00000542-200402000-00009.

6. Antonelli M, Moro ML, Capelli O, De Blasi RA, D’Errico RR, Conti G, et al. Risk factors for early onset pneumonia in trauma patients. Chest 1994; 105: 224-228, doi: 10.1378/ chest.105.1.224.

7. Lepelletier $D$, Roquilly $A$, Demeure dit latte $D$, Mahe $P J$, Loutrel O, Champin P, et al. Retrospective analysis of the risk factors and pathogens associated with early-onset ventilator-associated pneumonia in surgical-ICU head-trauma patients. J Neurosurg Anesthesiol 2010; 22: 32-37, doi: 10.1097/ANA.0b013e3181bdf52f.

8. Stover JF, Stocker R. Barbiturate coma may promote reversible bone marrow suppression in patients with severe isolated traumatic brain injury. Eur J Clin Pharmacol 1998, 54: 529-534, doi: 10.1007/s002280050508.

9. Nadal P, Nicolas JM, Font C, Vilella A, Nogue S. Pne in ventilated head trauma patients: the role of t ner therapy. Eur J Emerg Med 1995; 2: 14-16, 00063110-199503000-00004.

10. Hyllienmark $P$, Brattstrom $O$, Larsson $F$ ing $C R$, Petersson J, Oldner A. High incidence of post-injury , umonia in intensive care-treated trauma p $\ldots$. Acta Ana sthesiol Scand 2013; 57: 848-854, doi: 1 111/aas "111.

11. Rondeau N, Cinotti R, Rozec B, oquilly Floch $\mathrm{H}$, Groleau N, et al. Dobutamine-induced not prevent vasospasm in su a randomized controlled pilot dy. $\quad$ rit Care 2012;17: 183-190, doi: 10.1007/s12028-c, 32-y.

12. Roberts I, Sydenha Barbi ates for acute traumatic brain injury. Cochra Data use Sys Rev 2012; 12: CD000033.

13. Bederson JB, Cu Batjer HH, Dacey RG, Dion JE, Dirir or MN, al. Guidelines for the management of aneury ubarach d hemorrhage: a statement for healthcar proi onals from a special writing group of the Stroke ouncil, Am an Heart Association. Stroke 2009; 40: 994.025 'oi: 10.1161/STROKEAHA.108.191395.

14. K Kazai วv $C$ t al. ESPEN Guidelines on Enteral Nutrition: nsive e. Clin Nutr 2006; 25: 210-223, doi: 10.1016/ h... 006.01 .021

soles Ju, Bion J, Connors A, Herridge M, Marsh B, Melot C, al. Weaning from mechanical ventilation. Eur Respir $J$ 2.J7; 29: 1033-1056, doi: 10.1183/09031936.00010206.

16. Rumbak MJ, Newton M, Truncale T, Schwartz SW, Adams JW, Hazard PB. A prospective, randomized, study comparing early percutaneous dilational tracheotomy to prolonged translaryngeal intubation (delayed tracheotomy) in critically ill medical patients. Crit Care Med 2004; 32: 16 -1694, doi: 10.1097/01.CCM.0000134835.05161.B6

17. Gruson $D$, Hilbert $G$, Vargas $F$, Valentino $R, B C$ ar $C$ Allery $A$, et al. Rotation and restricted use of antio $s$ in medical intensive care unit. Impact on the incia of ventilator-associated pneumonia causec antibiotic-resistant gram-negative bacteria. Am J Respir Crm are N/2000; 162(Part 1): 837-843, doi: $10.11 \quad \mathrm{ccm}$.1 905050.

18. Deknuydt F, Roquilly A, Cinott , Altare Asehnoune K. An in vitro model of mycobacte granulc a to investigate the immune response in br injul 2013; 41: 245-254, doi' J.10. CMI.UD013e3182676052.

19. Meisel C, Schwab JN rass K, M el A, Dirnagl U. Central nervous system in; fir ed immune deficiency syndrome. Nat Rev Neurosci-2005; 6: -286, doi: 10.1038/nrn1765.

20. Marik PE, Z? ga P. Early enteral nutrition in acutely ill patients: ? yster tin review. Crit Care Med 2001; 29: 2264-2270, J.100r00003246-200112000-00005.

21. Poulard F, Dim Martin-Lefevre L, Bontemps F, Fiancette $M, \quad+i E, t$ al. Impact of not measuring residual gastr volr mechanically ventilated patients receiving ea iteral feeding: a prospective before-after study. J Paren Enteral Nutr 2010; 34: 125-130, doi: 10.1177/ 0148607 is 9344745.

22. ignier J, Mercier E, Le Gouge A, Boulain T, Desachy A, $B$ ec $F$, et al. Effect of not monitoring residual gastric ume on risk of ventilator-associated pneumonia in adults eceiving mechanical ventilation and early enteral feeding: a randomized controlled trial. JAMA 2013; 309: 249-256, doi: 10.1001/jama.2012.196377.

23. Roquilly A, Cinotti R, Jaber S, Vourc'h M, Pengam F, Mahe PJ, et al. Implementation of an evidence-based extubation readiness bundle in 499 brain-injured patients. a before-after evaluation of a quality improvement project. Am J Respir Crit Care Med 2013; 188: 958-966, doi: 10.1164/rccm.20130101160C.

24. Mocsai A, Jakus Z, Vantus T, Berton G, Lowell CA, Ligeti E. Kinase pathways in chemoattractant-induced degranulation of neutrophils: the role of p38 mitogen-activated protein kinase activated by Src family kinases. J Immunol 2000; 164: 4321-4331, doi: 10.4049/jimmunol.164.8.4321.

25. Asehnoune K, Roquilly A, Abraham E. Innate immune dysfunction in trauma patients: from pathophysiology to treatment. Anesthesiology 2012; 117: 411-416, doi: 10.1097/ ALN.0b013e31825f018d.

26. Yu HP, Chaudry IH. The role of estrogen and receptor agonists in maintaining organ function after trauma-hemorrhage. Shock 2009; 31: 227-237, doi: 10.1097/SHK.0b013e3181 $8347 \mathrm{e} 7$.

27. Agbaht K, Lisboa T, Pobo A, Rodriguez A, Sandiumenge A, Diaz E, et al. Management of ventilator-associated pneumonia in a multidisciplinary intensive care unit: does trauma make a difference? Intensive Care Med 2007; 33: 1387-1395, doi: 10.1007/s00134-007-0729-5.

28. Chastre J, Wolff M, Fagon JY, Chevret S, Thomas F, Wermert D, et al. Comparison of 8 vs 15 days of antibiotic therapy for ventilator-associated pneumonia in adults: a randomized trial. JAMA 2003; 290: 2588-2598, doi: 10.1001/jama.290.19.2588. 